\title{
Precision sowing of vegetable seeds using electrically operated distribution devices
}

\author{
Adriana Muscalu ${ }^{1, *}$, Cătălina Tudora ${ }^{1}$, Laurențiu Vlăduțoiu ${ }^{1}$, Constantin Vlad $^{2}$, and \\ Angela Dorogan ${ }^{3}$ \\ ${ }^{1}$ INMA, 6 Ion Ionescu de la Brad Blvd., Bucharest, 013811, Romania \\ ${ }^{2}$ SCDL, 23 Mesteacanului Street, Buzău, 120024, Romania \\ ${ }^{3}$ INCDPT, 6 Ion Ionescu de la Brad Blvd., Bucharest, 013811, Romania
}

\begin{abstract}
The high efficiency of vegetable crops is influenced, in addition to soil preparation works, weed, diseases and pests control, irrigation, etc. by precision sowing, which involves placing a certain number of seeds at an exact depth and distance. Thus, cost savings, a high reliability of production and especially a greater uniformity of crops are achieved, most often uniform and quality productions being obtained. For vegetable species in the case of which harvesting is practiced only once, uniformity of seed distribution is particularly important. In most cases, vegetable seeds have small size, irregular shape and small mass. These characteristics make the development of precision seeders for this type of seed quite difficult. Precision sowing of vegetable seeds ensures a correct sowing rate, which implies an optimal space for plant growth and development, thus improving crop yields. The paper presents a summary of the current state of precision seeders equipped with electrically operated distributors for vegetable seeds, as well as the preliminary results of research conducted by authors in this field.
\end{abstract}

\section{Introduction}

Precision agriculture aims to optimize agricultural production and environmental quality, being defined as a complex system that applies advanced technologies combined with agricultural management practices and crop-specific information, taking into account aspects of their temporal and spatial variability $[1,2,3,4,5]$. In the current context, it can contribute substantially to meeting the market demand for agricultural products, increasingly oriented towards healthy and high quality products $[6,7,8]$.

Precision sowing is a way to apply the general and current concept described above. The improvement of specialized equipment, which can perform this operation with precision for various types of crops, is a continuous concern for specialists in the field [9, $10,11]$.

For vegetable crops, the placement of the correct amount of seeds per unit area, respecting the prescribed sowing depth, together with achieving uniformity of distance between seeds on the row and between rows, significantly influences the yield. A correct

\footnotetext{
* Corresponding author: amuscalis@yahoo.com
} 
distribution of vegetable seeds is the premise of crops with uniform and quality production, achieving cost savings $[3,10,12]$.

The efficiency of vegetable crops, especially of those with only one harvest per year, is conditioned by the uniform distribution of seeds in the soil, in addition to land preparation, irrigation, crop maintenance, etc. The correct sowing norm ensures a better germination and an optimal space for plant development, with weed suppression effects [13, 14]. Also, weed control works in vegetable crops can be done efficiently, both by using classical and intelligent systems, knowing that these crops, compared to others, have a high sensitivity to attack by harmful plants. $[15,16,17,18]$

For most vegetable species, the seeds have irregular shapes, small mass and small size (average diameter $<3 \mathrm{~mm}$ ), so the development of dedicated precision seeders is quite difficult $[19,20]$.

Numerous research units and companies producing agricultural machines have dealt with the study and development of electrically operated distribution devices, intended for precision sowing. Of these, some have interesting technical features.

The research and results presented in the paper are a premise for optimizing precision seeders for vegetable seeds.

\section{Electrically operated distribution devices}

\subsection{The current state of electrically operated distribution devices}

Large companies producing precision seeders have developed and implemented electrically operated distribution devices intended mainly for maize, soybean, sunflower, sugar beet seeds.

John Deer implemented the type of row unit ExactEmerge тм (fig.1), electrically driven, which uses the "Brush Belt Delivery System", patented by John Deere company. This system refers to the replacement of the seed driving tube with a brush belt that places the seeds, in the furrow according to the agrotechnical norms of corn and soybean crops, especially at high working speeds (over $12 \mathrm{~km} / \mathrm{h}$ ). The ExactEmerge $\mathrm{CM}^{\mathrm{TM}}$ electric drive system is powered by two brushless motors, on each unit, that work independently to control the meter and the BrushBelt. During the distribution process, the seeds pass in front of a sensor, each row unit is equipped with this. It has the role of monitoring the singularity, the precision of the distance and the seed norm [21].

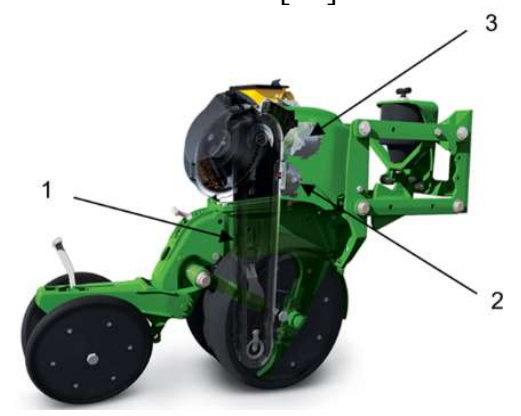

Fig.1 Row unit ExactEmerge ${ }^{\mathrm{TM}}(1$ - brush system for seed transport; 2 - electric drive motor of meter; 3 - BrushBelt electric drive motor) [21]

MaxEmerge TM 5 is a new type of row units, electrically driven, used for 1775 NT pneumatic planter (produced by John Deer), so that maize and soybean can be sown with precision at high working speeds of $16 \mathrm{~km} / \mathrm{h}[21]$. 
Kinze company produces seed meters (4000 series), vacuum driven distributors with electric drive (fig.2), which achieve a seed distribution precision of $99 \%$, at sowing speeds of over $10 \mathrm{~km} / \mathrm{h}$. The seeder discs have a configuration that ensures the filling of all the holes, in order to prevent the appearance of gaps when sowing. For this, some channels were made on the surface of the discs with the role of directing the seeds $[11,21]$.

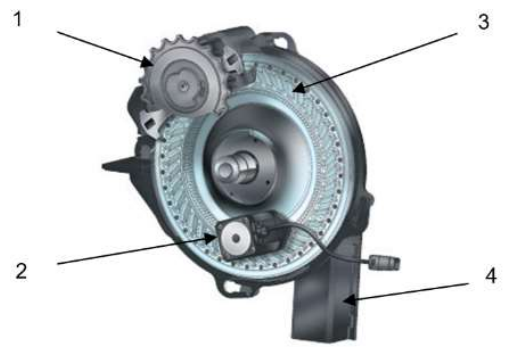

Fig.2 Seed meter Kinze 4000 series ( 1 - scraper; 2 - electric motor; 3 - seeder disc; 4 - seed driving tube) [21]

For precision sowing of beet seeds at the Department of Environment, Resources and Technology at the Royal Veterinary and Agricultural University KVL, Denmark, a precision planter with electric drive was developed. For driving, stepper electric motors were used, providing high-precision control for the seed distribution discs. In addition, the seeds are monitored electronically, their position being permanently known. Thus, it was possible to determine the points of fall, respectively their placement points. Have been used 4 row units mounted on a Kverneland Accord seeder, Germany, Kleine Unicorn 3, attached to an autonomous tractor. A GPS-controlled lateral displacement system (own conception) was also used to synchronize seed distribution and transverse overlap, which guides the aggregate to predefined virtual field passes [22].

The machine was tested in the laboratory to evaluate the uniformity of the distance between the seeds and the synchronization of the seeder units on the working width. Thus, it was found that the standard deviation of the distances between seeds on the row is very small, the electric motors being able to operate the distribution disks with precise and constant speed [22].

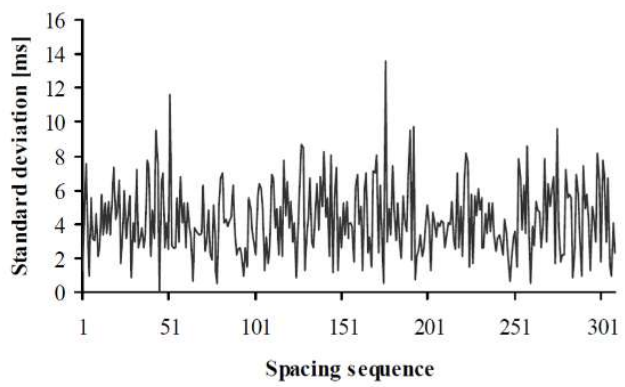

Fig. 3. Synchronization of the four seeder units expressed in standard deviation versus spacing sequence (for $6000 \mathrm{~Hz}$ motor speed) [22]

To evaluate the synchronization, the standard deviation of the accumulated time per seed detection was determined, for the same spacing sequence, between the four row units. The values of this parameter shown in Figure 3 were in a constant range during the test, which shows that the seed distribution is synchronous across the working width. The 4 row units place the beet seeds in the soil, at about the same time. This synchronization is important for the efficiency of the maintenance works, which can be performed longitudinally and transversely to the rows, in the crop [22]. 
Wendte K.W. is the author of a patent that refers to a seed distributor with electric drive (fig. 4). It consists of a seed plate (4) rotatably mounted concentrically in the meter housing (7) for singulating the seeds. The seed plate is driven by a gear transmission. The gear 2 is mounted on the electric motor shaft. The intermediate gear 3 has the same number of teeth, having the role of ensuring the correct direction of the distribution disc. The distribution disc provided with seed holes (6), is in fact a gear, made so that the transmission ratio is $1: 5$, so that its rotation speed will not exceed $600 \mathrm{rpm}$. The electric motor is connected via connectors (4) to a controller and a power supply, connected to the tractor's $12 \mathrm{~V} \mathrm{DC}$ electrical system. The roe unit is equipped with sensors connected to the controller to determine the working speed during the sowing operation [23].

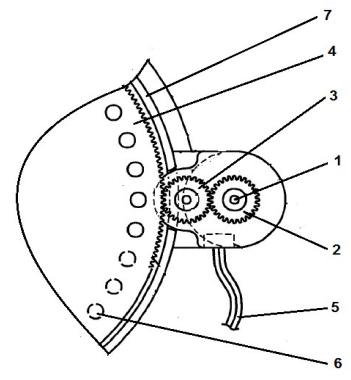

Fig. 4 Side view of the electric drive system of the seed plate [23]

For small vegetable seeds, with diameters between 2-10 $\mathrm{mm}$, an electric precision seeder prototype was developed and tested. During the sowing operation, the seeder is electrically operated. It is also equipped with a sowing quality monitoring system consisting of the following main elements: Holzer speed measuring sensor, sowing monitoring fibre sensor, controller, computer, display etc., plus the host computer software. The seeder (fig. 5 ) is intended for use on small areas. The equipment uses a powerful brushless DC motor installed in the rear wheel, which can adjust the speed of travel, thus providing the necessary running power to save labour and improve efficiency. The seeder is equipped with 4 seeding units, each having distribution discs, interchangeable, depending on the type of seeds [19].
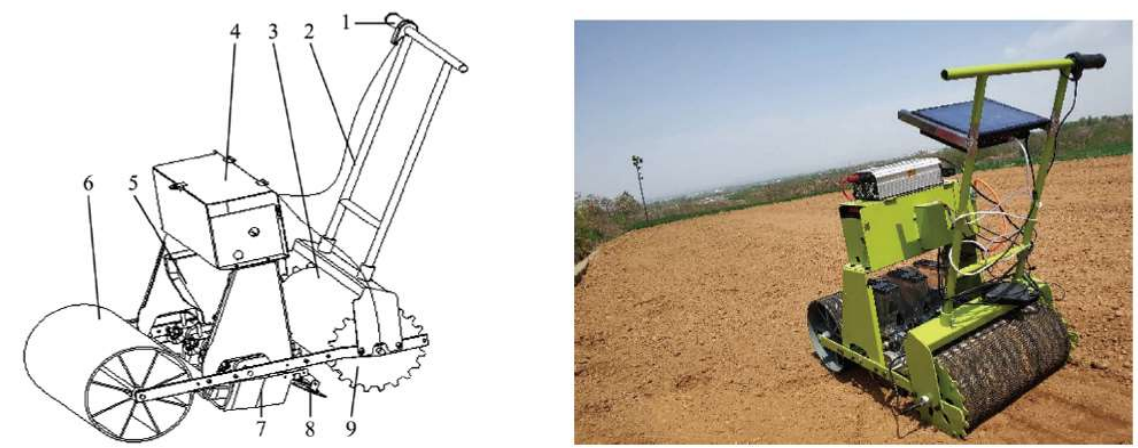

Fig. 5 Overall structure sketch and overview of prototype [19]

According to overall structure sketch, the seeder consists of: 1. Speed governing knob, 2. Rack, 3. Rear repression wheel, 4. Power supply box, 5. Seeding unit, 6. Front pressing wheel, 7. Ditching device, 8. Earthing device, 9. Built-in drive motor. The construction of the seeder allows the quick change of the sowing disc, as well as the easy adjustment of the distance between the rows and of the sowing depth, according to each crop's cultivation technology. 
The monitoring system can perform control functions of the sowing operation during the operation of the equipment, of its starting or stopping. It can check the correct selection of the distributor disc by correlating it with the seed diameter. When the distributor disc works, the type of seeds, the sowing conditions, the number of seeds, etc. are displayed. The system can detect the lack of sowing, being equipped with an alarm function. The structure of the system is designed for easy use [19].

Field experiments were performed for coriander seeds, Chinese cabbage and radishes. Thus, using the distribution discs suitable for each type of seed, a sowing precision of over $95 \%$ was obtained for each species. At the working speeds of the seeder of $3 \mathrm{~km} / \mathrm{h}$ and 4 $\mathrm{km} / \mathrm{h}$, the relative error of the monitoring precision of the system was less than $6 \%$ [19].

\subsection{Research on the realization and experimentation of a vegetable seed distributor with electric drive}

\subsubsection{Material and Methode}

INMA Bucharest designed and made an Experimental Model of an Electrically operated vegetable seed distributor (fig.6) consisting of the following main subassemblies: 1. seed box, 2 . box lid, 3. assembled depression chamber, 4. gear motor, electrically operated, 5. supply chamber, 6. distribution disc. The distribution disc has a ring shape, having 2 rows of large and small holes, respectively, on the outer circumference, for bean and onion seeds.
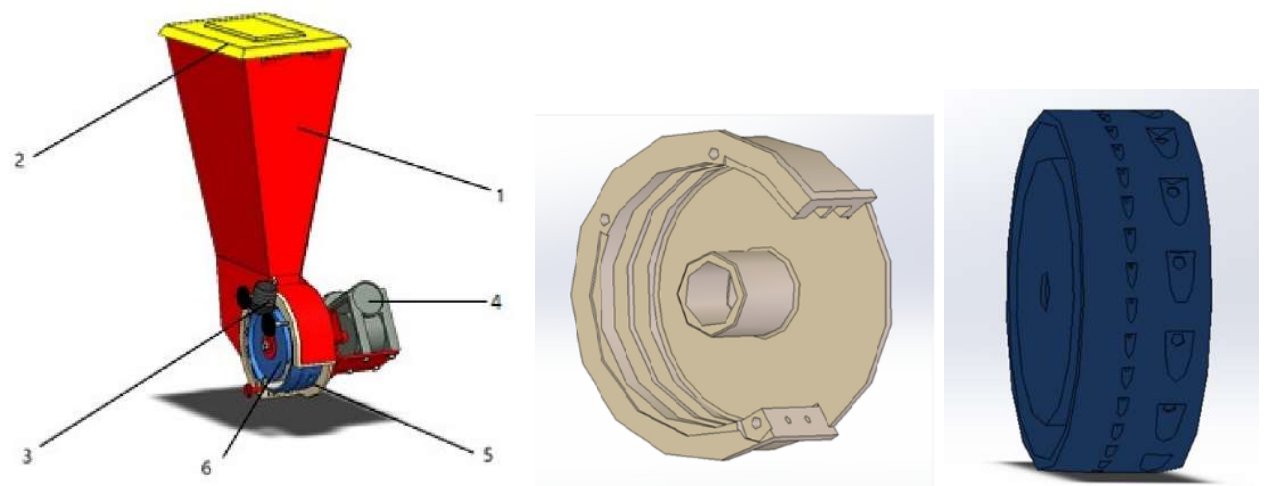

Fig. 6 Vegetable seed distributor, Supply chamber, Seed distribution disc 3D modeled with SolidWorks program

There are 32 small holes and 14 large holes in order to ensure a distance between seeds, in a row, of $30 \mathrm{~mm}$ for onion and $200 \mathrm{~mm}$ for bean, respectively, according to cultivation technologies. Depending on the type of seed, the distribution disc slides on the drive shaft bringing one of the rows of holes into the supply chamber. Both the supply chamber and the distribution disc were made of composite materials, through $3 \mathrm{D}$ printing technology.

For the experiments carried out in the laboratory, 2 species of vegetable seeds were used: for large seeds - garden bean Doina variety and for small seeds - onion Aurie de Buzau variety, (fig.7). 

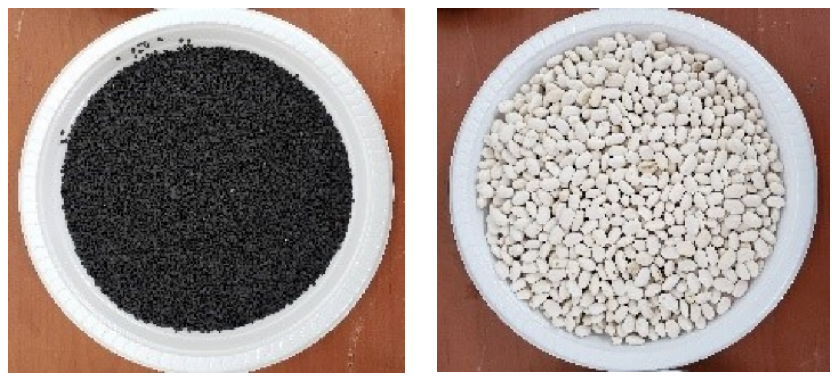

Fig. 7 Types of seeds used in experiments (left - onion, right - bean)

The seed distributor was tested in the laboratory, at INMA. For experimentation, the aim was to verify the distributor's mechanical principle of operation, emphasizing the determination of the distribution norm coefficient of variation, without pneumatic input. For this, the assembly consisting of the seed supply box and the seed distributor was mounted on a support, after which the scraper was adjusted according to the dimensions of the seeds. The seed supply box was loaded at a filling level considered so that, after the tests, the seed level is above the slots in the bottom of the box and on the seed distributor, more precisely in the supply chamber.

For a working speed of $3 \mathrm{~km} / \mathrm{h}$, the disc rotation frequency was $52 \mathrm{rpm}$ for onions and $18 \mathrm{rpm}$ for beans. A stabilized voltage source was used to power the electric motor, for which the value of the supply voltage of $18 \mathrm{Vdc}$ for onion and $7 \mathrm{Vdc}$ for bean was set.

Tests were performed in three repetitions, over a period of $60 \mathrm{~s}$, for each of them and for each type of seed, respectively. The seeds were collected in the container and weighed after each test. The following indicators were determined: average mass, empirical standard deviation and variation coefficient of the distribution norm.

Average seed mass:

$$
M_{m}=\frac{\sum M i}{n},[\mathrm{~g}]
$$

where: $\mathrm{M}_{\mathrm{i}}$ is the mass obtained in the test " $\mathrm{i}$ ";

$\mathrm{n}=$ number of repetitions.

Empirical standard deviation:

$$
\sigma_{N}=\sqrt{\frac{\sum\left(M_{i}-M_{m}\right)^{2}}{n-1}}
$$

Variation coefficient of the distribution norm:

$$
C_{V N}=100 \cdot \frac{\sigma_{N}}{M_{m}},[\%]
$$

\subsubsection{Results}

\begin{tabular}{|c|c|c|c|c|c|c|}
\hline $\begin{array}{l}\text { Seed } \\
\text { type }\end{array}$ & $\begin{array}{c}\text { Adjustment } \\
\text { parameters } \\
\text { T, U, n }\end{array}$ & Repetition & $\begin{array}{l}\text { Mass } \\
\text { M [g] }\end{array}$ & $\begin{array}{c}\text { Average } \\
\text { mass } \mathbf{M}_{\mathbf{m}} \\
{[\mathrm{g}]}\end{array}$ & $\begin{array}{c}\text { Empirical } \\
\text { standard } \\
\text { deviation }\end{array}$ & $\begin{array}{c}\text { Variation } \\
\text { coefficient of the } \\
\text { distribution } \\
\text { norm [\%] }\end{array}$ \\
\hline \multirow{3}{*}{ Onion } & \multirow{3}{*}{$\begin{array}{l}\text { Time } \mathrm{T}=60 \mathrm{~s} \\
\text { Voltage } \\
\mathrm{U}=18 \mathrm{Vdc} \\
\text { Disc speed } \\
\mathrm{n}=52 \mathrm{rpm}\end{array}$} & $\mathrm{R} 1$ & 28.50 & \multirow{3}{*}{27.87} & \multirow{3}{*}{0.79} & \multirow{3}{*}{2.84} \\
\hline & & $\mathrm{R} 2$ & 26.98 & & & \\
\hline & & R3 & 28.13 & & & \\
\hline
\end{tabular}

The results obtained are presented in table 1 .

Table 1. Experimental results. 


\begin{tabular}{|c|l|c|c|c|c|c|}
\hline \multirow{2}{*}{ Bean } & $\begin{array}{l}\text { Time T=60 s } \\
\text { Voltage } \\
\text { U=7 Vdc } \\
\text { Disc speed } \\
\mathrm{n}=18 \mathrm{rpm}\end{array}$ & $\mathrm{R} 1$ & 190.16 & \multirow{2}{*}{192.69} & 6.24 & 3.24 \\
\cline { 3 - 4 } & $\mathrm{R} 3$ & 188.11 & 199.80 & & \\
\hline
\end{tabular}

Aspects during the experiments performed within INMA are presented in figure 8 .
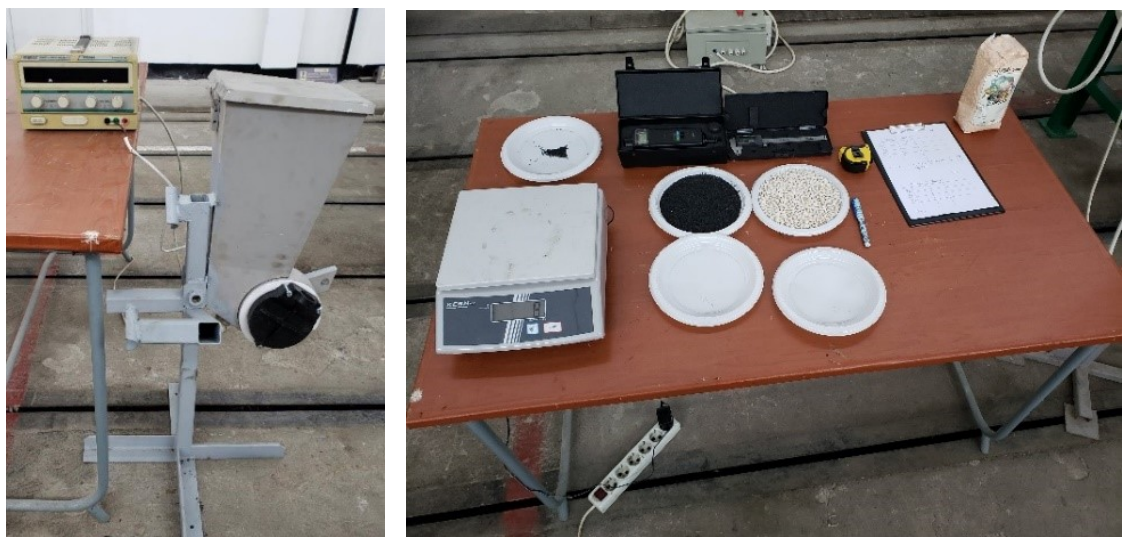

Fig. 8 Experimenting the electrically operated vegetable seed distributor

For INMA-type electrically operated vegetable seed distributor, intended for large and small seeds, at the recommended working speed was obtained a variation coefficient of the distribution norm of $2.84 \%$ for onions and $3.24 \%$ for beans, respectively, values that fall below the maximum value accepted by the specific norms (max. 5\%).

\section{Conclusions}

The experiments showed that for INMA-type electrically operated vegetable seed distributor, the values obtained for the variation coefficient of the distribution norm were lower for the small seeds than those for larger seeds, however both values were found within the allowed limits.

Given that the distributor will operate exhaustively, it is expected to obtain lower variation coefficients of the norm, increasing the sowing precision.

By using electric motors, characterized by high reliability, to drive the seed distributors, the mechanical transmission elements that usually require additional adjustments and high maintenance are eliminated. Thus, the power supply of the seed distributors represents an efficient way to maintain the uniformity of the seed distribution and implicitly to achieve a precision sowing, according to the current trends.

"The work was supported by a grant of the Romanian Ministry of Research and Innovation, CCCDI UEFISCDI project number PN-III-P1-1.2-PCCDI-2017-0659/ No.11 PCCDI/2018, within PNCDI III".

\section{References}

1. A. Nabi, S, Narayan, B. Afroza, F. Mushtaq, S. Mufti, H.M. Ummyiah, A. Malik, Journal of Pharmacognosy and Phytochemistry, 6, (6), 6, (2017) 
2. F. J. Pierce, P. Nowak, Aspects of Precision Agriculture, Advances in Agronomy, 67, $86,(1999)$

3. E. M. Brandelero, P. F. Adami, A. J. Modolo, M. M. Baesso, A.J. Fabian, Journal of Agronomy 14 (3), 7, (2015);

4. A. Balafoutis, B. Beck, S. Fountas, J. Vangeyte, T. van der Wal, I. Soto, M. GómezBarbero, A. Barnes, V. Eory, Sustainability 9, 1339; 28, (2017)

5. D. Cujbescu, Gh. Voicu, Gh. Bolintineanu, V. Vlăduţ, D. Manea, C. Persu, S. Bungescu Comparative study regarding the sowing precision of precision sowing machines distribution devices, Proceedings of The 43 International Symposium on Agricultural engineering "Actual Tasks on Agricultural Engineering", Opatija, Croatia, $24^{\text {th }}-27^{\text {th }}$ February $2015,12,(2015)$;

6. L. Trivelli, A. Apicella, F. Chiarello, R. Rana, G. Fantoni, A. Tarabella, British Food Journal, 121, 8, 14, (2019)

7. D. Cujbescu, V. Vlăduţ, Gh. Voicu, N. Ungureanu Researches on obtaining higher qualitative indices for the sowing work, $15^{\text {th }}$ International Scientific Conference "Engineering for Rural Development", Proceedings, (15), Jelgava, Latvia, $25^{\text {th }}-27^{\text {th }}$ May 2016, 6, (2016);

8. S. P. Singh, Mukesh K Singh, U. Ekka, M. K. Singh, Indian Journal of Agricultural Sciences 89 (12), 5, (2019)

9. D. Cujbescu, S.St. Biriș, Gh. Voicu, M. Matache, G. Paraschiv, V. Vlăduţ, M. Bularda, INMATEH Agricultural Engineering, 61, 2, 8, (2020)

10. V.P. Khambalkar, D.S.Karale, U.S. Kankal, Internat. J. Agric. Eng., 7 (1), 4, (2014)

11. N. Sharaby, A. Doroshenko, A. Butovchenko, A. Legkonogih, E3S Web of Conferences 135, 01080 (2019)

12. T. Kaur, D. Kumar, International Journal of Computer Science, Engineering and Applications (IJCSEA) 3, (3) 8, 2013

13. E.A. Alhassan, D.A. Adewumi, B. Okpodjah, International Journal of Mechanical Engineering and Technology (IJMET), 9 (10) 8, (2018)

14. T. V. Maxsudovich, M. G. Usmonjonovich, K. S. Rasuljonovich, R. A. Yakubjonovich IJSTR 9 (9), 7, (2020)

15. E. Pannaci, B. Lattanzi, F. Tei, J. Crop Protection 96, 15, (2017)

16. S. Korav, A. K. Dhaka, R. Singh, N. Premaradhya, G. Chandramohan Reddy, Journal of Pharmacognosy and Phytochemistry 7 (4), 6, (2018)

17. S. A. Fennimore, D. C. Slaughter, M. C. Siemens, R. G. Leon, M. N. Saber, Weed Technology 30 (4), 15, (2016)

18. B. Melander, B. Lattanzi, E. Pannacci, Crop Protection 72, 8, (2015)

19. X. Jin, Q. W. Li, K. X. Zhao, B. Zhao, Z.T. He, Z. M. Qiu, Int J Agric \& Biol Eng, 12 (2), 7, (2019)

20. .Z. Gobor, H. Heuberger, R. Rinder, Precision plot seeder for medicinal and aromatic plants - concept, development and optimisation, Hungarian Agricultural Engineering (HAG) 27, 5, (2015)

21. C. Persu, D. Cujbescu, E. Marin, G. Gheorghe, C. Vlad, F. Burnichi, O. Kabas, Seed meters with electric drive at precision seeders, Proceeding International Symposium, ISBINMATEH 2019, 4, (2019)

22. H.W. Griepentrog, P.T. Skou, J.F. Soriano, B.S. Blackmore, Design of a seeder to achieve highly uniform sowing patterns, $5^{\text {th }}$ European Conference on Precision Agriculture, Uppsala, Sweden, $9^{\text {th }}-12^{\text {th }}$ June 2005, 8, (2005);

23. Keith W. Wendte, Direct drive electric seed metering system, Patent no. U.S. 7,617,785 B2/ 17 Nov. 2009. 